\title{
Implementasi Jaringan Hotspot Di Perkantoran Guna Meningkatkan Keamanan Jaringan Komputer
}

\author{
Mokhamad Gustiawan ${ }^{1}$, Ristu Juli Yudianto ${ }^{2}$, \\ Johanes Pratama ${ }^{3}$ Abdurahman Fauzi ${ }^{4}$ \\ mochhamadgustiawan17@gmail.com ${ }^{1}$, juliyudiantorestu@gmail.com², \\ johanespratama09@gmail.com ${ }^{3}$, abdurahman.auz@ars.ac.id ${ }^{4}$ \\ Teknik Informatika, Fakultas Teknologi Informasi, Adhirajasa Reswara Sanjaya (ARS) \\ Antapani, Jl. Terusan Sekolah No.1-2, Cicaheum, Kec. Kiaracondong, Kota Bandung, Jawa Barat 40282
}

\begin{abstract}
Abstrak-Tujuan penelitian adalah untuk menganalisis dan melakukan implementasi jaringan hotspot dan pada Perkantoran sehingga kantor dapat memberikan fasilitas hotspot berbasis mikrotik, membagi bandwidth pada jaringan hotspot secara merata kepada setiap pelanggan dan membatasi penggunaan bandwidth sesuai dengan waktu yang tertera pada paket voucher. Metode penelitian yang dilakukan meliputi metode analisis yaitu dengan terhadap sistem yang sedang berjalan, metode perancangan topologi jaringan yaitu dengan memilih perangkat jaringan yang akan digunakan dan konfigurasi pada setiap perangkat jaringan yang digunakan, melakukan testing jaringan baru, dan kegiatan maintenance. Hasil penelitian yang didapat adalah implementasi rancangan topologi jaringan hotspot dengan menggunakan Mikrotik RouterOS yang dapat mengoptimalkan kinerja jaringan hotspot dan memaksimalkan bandwidth pada jaringan hotspot. Simpulan dari penelitian ini adalah dengan digunakannya Mikrotik RouterOS pada jaringan hotspot, maka admin dapat membatasi penggunaan bandwidth pelanggan berdasarkan paket voucher yang telah dibuat dan tidak terjadi tarik menarik bandwidth antar pelanggan karena pembagian bandwidth yang sama rata.
\end{abstract}

Kata Kunci: Mikrotik RouterOS, Hotspot

Abstract - The purpose of this study is to analyze and implement hotspot networks and in offices so that offices can provide mikrotik-based hotspot facilities, distribute bandwidth on hotspot networks evenly to each customer and limit bandwidth usage according to the time stated on the voucher package. The research methods carried out include analytical methods, namely with the current system, network topology design methods, namely by selecting network devices to be used and configuring each network device used, testing new networks, and maintenance activities. The results obtained are the implementation of the hotspot network topology design using Mikrotik RouterOS which can optimize the performance of the hotspot network and maximize bandwidth on the hotspot network. The conclusion of this research is that by using Mikrotik RouterOS on a hotspot network, the admin can limit the bandwidth usage of customers based on the voucher packages that have been made and there is no tug of war between customers because of the equal distribution of bandwidth.

Keywords: Mikrotik RouterOS, Hotspot

\section{Pendahuluan}

Kemajuan yang sangat pesat di bidang teknologi, terutama dalam teknologi informasi komputer, mendorong munculnya inovasi baru dalam penyajian informasi untuk memenuhi kebutuhan informasi[1]. Seiring perkembangannya teknologi, kebutuhan untuk mengelola layanan menjadi lebih cepat dan mudah sudah menjadi tuntutan baru saat ini. Pemanfaatan jaringan internet di dunia kian meningkat, hal yang bisa dilihat dengan gencarnya perkembangan mobile application, cloud computing yang berbasiskan jaringan internet. Tak terkecuali Indonesia yang merupakan salah satu negara berkembang yang menggunakan internet. Jumlah penggunaan jaringan internet meningkat sangat pesat pada tahun 2017 mencapai 143,26 juta jiwa atau setara dengan 54,68 persen dari total jumlah penduduk Indonesia. Jumlah tersebut menunjukan kenaikan sebesar 10,56 juta jiwa dari hasil survei pada tahun 2016 oleh Asosiasi Penyelenggara Jasa Internet Indonesia (APJII).

Hotspot (Wi-Fi) merupakan suatu area dimana suatu koneksi internet dapat berlangsung tanpa kabel. Jaringan Wi-Fi (Wireless Fidelity) menjadi teknologi alternatif dan relatif lebih mudah untuk diimplementasikan di lingkungan kerja[2]. Hotspot (Wi-Fi) juga merupakan salah satu bentuk pemanfaatan teknologi pada lokasi-lokasi publik seperti taman, perpustakaan, restoran, kampus,perkantoran ataupun bandara, beberapa diantaranya bahkan dapat diakses secara cuma-cuma. Internet terkoneksi biasanya dilakukan melalui perangkat notebook/ laptop/ PDA. Hotspot (Wi-Fi) pertama kali digagas tahun 1993 oleh Breet Stewart. Dengan teknologi ini, individu dapat mengakses jaringan seperti internet melalui komputer atau laptop yang user miliki dilokasi-lokasi dimana hotspot (Wi-Fi) disediakan. 
Setiap jaringan mempunyai pengelolaan yang berbeda-beda sesuai dengan kebutuhuan itu sendiri. Tiap bagian mempunyai aturan-aturan tersendiri untuk mengatur alur keluar masuk traffic jaringan, sebagai contoh kecepatan akses internet untuk admin lebih baik dari pegawai yang tidak terlalu menggunakan nya[3]. Selain itu juga penerapan hotspot menjadikan autentikasi bagi pengguna yang akan menggunakan internet melalui username dan password lebih termanajemen dengan baik dan termonitor[4]. Dengan adanya jaringan Hotspot ini, secara langsung membentuk management security yang memiliki tujuan untuk memastikan bahwa sistem keamanan yang sudah dibuat tidak bisa dilanggar[5]. Oleh karena itu penelitian ini menjadi penting, dengan mengimplementasikan jaringan hotspot pada sebuah perkantoran yang memiliki akses pengguna yang banyak.

\section{Landasan Teori}

Wireless network atau jaringan tanpa kabel adalah salah satu jenis jaringan berdasarkan media komunikasinya, yang memungkinkan perangkat-perangkat di dalamnya seperti komputer,hp,dll bisa saling berkomunikasi secara wireless/tanpa kabel.Wireless network umumnya diimplementasikan menggunakan komunikasi radio.Implementasi ini berada pada level lapisan fisik (pysical layer) dari OSI model.

\subsection{Wireless PAN (WPAN)}

Wireless personal Area Network (WPAN) adalah jaringan wireless dengan jangkauan area yang kecil.Contohnya Bluetooth,Infrared, dan Zigbee.

\subsection{Wireless LAN (WLAN)/Wifi}

Wireless Local Area Network (WLAN) atau biasa disebut Wifi memiliki jangkauan yang jauh lebis luas dibanding WPAN. Saat ini WLAN mengalami banyak peningkatan dari segi keepatan dan luas cakupannya . Awalnya WLAN di tujukan untuk penggunaan perangkat jaringan lokal, namun saat ini lebih banyak digunakan untuk mengakses internet

\subsection{WMAN (Wireless Metropolitan Area Networks)}

WMAN memiliki cakupan jaringan yang cukup luas hingga jarak mencapai 31 mil atau sekitar $50 \mathrm{~km}$. Jaringan ini memungkinkan untuk tetap menghubungkan beberapa lokasi meski terhalang bangunan. WMAN sering kali digunakan untuk menghubungkan jaringan beberapa fakultas dalam satu universitas yang tersebar. Jaringan ini mengandalkan gelombang radio dan sensor infrared dalam pengiriman data.

\subsection{WWAN (Wireless Wide Area Network)}

WWAN merupakan jaringan nirkabel dengan cakupan jangkauan yang lebih luas dibandingkan WLAN.Teknologi WWAN memungkinkan pemakainya untuk membangun koneksi di area yang sangat luas, bahkan bisa mencakup sebuah kota maupun negara.Umumnya, penyedia layanan ini menggunakan sejumlah antena dengan mengusung sistem satelit di dalamnya.

\subsection{Mikrotik RouterOS}

Mikrotik RouterOS adalah sistem operasi dan perangkat lunak yang dapat digunakan untuk menjadikan komputer manjadi router network yang handal, mencakup berbagai fitur yang dibuat untuk ip network dan jaringan wireless, cocok digunakan oleh ISP dan provider hotspot.(http://www.mikrotik.co.id/) Lisensi pada Mikrotik RouterOS adalah menggunakan level. Lisensi pada level disesuaikan dengan kebutuhan. Jika membutuhkan fitur yang lebih tinggi, maka level tersebut dapat ditingkatkan[4].

\subsection{Hotspot}

Hotspot adalah lokasi dimana user dapat mengakses melalui mobile computer (seperti laptop atau PDA) tanpa menggunakan koneksi kabel dengan tujuan jaringan internet (http://noc.eepis-its.edu/hotspot.php). Sistem hotspot pada mikrotik digunakan untuk memberikan layanan akses jaringan (internet/intranet) di Publik Area dengan media kabel maupun wireless. Hotspot menggunakan autentikasi untuk menjaga jaringan tetap walaupun bersifat publik. Sistem hotspot ini merupakan gabungan atau kombinasi dari beberapa fungsi dan fitur RouterOS menjadi sebuah sistem yang sering disebut 'Plug-nPlay' Access. Jaringan hotspot pada mikrotik bersifat bridge network Menu interface yang terdapat pada hotspot mikrotik.

Hotspot Server Profile digunakan untuk menyimpan konfigurasi- konfigurasi umum dari hotspot server. Profile ini digunakan untuk grouping beberapa hotspot server dalam satu router. Pada server profile terdapat konfigurasi yang berpengaruh pada user hotspot seperti metode autentikasi. Hotspot User Profile digunakan untuk menyimpan konfigurasi-konfigurasi umum dari user hotspot. Profile ini digunakan untuk grouping beberapa user. User Profile mampu melakukan assign pool ip tertentu ke group user. Parameter Time-out juga bisa diaktifkan untuk mencegah monopoli oleh salah satu user. Hotspot User adalah halaman dimana parameter username, password dan profile dari user disimpan.

\section{Metode Penelitian}

Dalam memperoleh data-data yang diperlukan untuk menunjang dan melengkapi kesempurnaan penelitian, Berdasarkan referensi definisi sejumlah model pengembangan system yang ada, dalam penelitian ini penulis menggunakan metode pengembangan system Network Development Life Cycle (NDLC). Desain yang 
diusulkan adalah desain topologi jaringan topolgi tree karena jika node salah satu jaringan (LAN / wireless) mengalami gangguan, maka node yang lainnya tetap dapat berfungsi kecuali ketika router utama (Mikrotik Routerboard) yang mengalami gangguan.

Hal ini akan meminimalisir gangguan pada jaringan hotspot jika jaringan LAN yang mengalami gangguan. Kemudian membuat 3 macam paket voucher akses internet menggunakan fitur User Manager pada Mikrotik RouterOS, yakni paket voucher 1 jam, 2 jam, dan 3 jam akses internet. Paket voucher akses internet digunakan untuk melimitasi penggunaan bandwidth pelanggan dengan hitungan per jam. Kecepatan bandwidth untuk setiap paket voucher disamakan berdasarkan aturan limitasi bandwidth yang telah dibuat sebelumnya.Kebutuhan aringan hardware dan software antara lain Tang crimping, Kabel UTP Konektor RJ45, Tester kabel jaringan, Router, dan Switch hub, kemudian untuk perangkat lunak yang dgunakan adalah windows 7 dan winbox.

\section{Hasil Dan Pembahasan}

Dalam proses implementasi jaringan ini dilakukan beberapa langkah yang terdiri dari konfigurasi router Mikrotik RB750 R2 menggunakan aplikasi windox, membuat hotspot login untuk konsumen dan pemilik, serta membatasi hak akses internet yang telah di tentukan sebelumnya oleh pihak pemilik dengan menggunakan fitur dari mikrotik yaitu firewall. Langkah berikutnya melakukan tahap evaluasi terhadap jaringan internet hotspot berbasis router mikrotik pada perkantoran yang meliputi pengujian terhadap penggunaan hotspot login, managemen bandwidth dan pengujian terhadap hak akses.

a) Konfigurasi awal Router Mikrotik

1. menghubungkan Router Mikrotik RB750 R2 Ke Laptop atau PC, lalu jalankan winbox dan pilih MAC address router yang sudah terhubung.

2. Menentukan IP address pada setiap port yang terhubung dengan router Mikrotik RB750. Port ether 2 adalah IP dari mikrotik yang terhubung ke router utama perkantoran. Port ether digunakan untuk access point

3. Dilakukan penentuan gateway pada mikrotik agar dapat terhubung ke router utama

4. Setting waktu server, guna mengetahui waktu login user ke hotspot login.

b) Hotspot Login

Konfigurasi hotspot dilakukan untuk membuat IP address hotspot, address pool dan DNS Name

1. Menentukan interface untuk hotspot yaitu ether 3, konfigurasi local address network yang berfungsi sebagai gateway hotspot login, menentukan pool address untuk access point perkantoran kedua 192.168.50.2- 192.168.50.100 dan DNS Name.

2. Untuk menggunakan fitur user manager harus mengaktifkan RADIUS server.

3. Melakukan konfigurasi hotspot user profile yang bertujuan untuk melimitasi bandwidth trial user yang terhubung.

c) Konfirgurasi User Manager

User manager merupakan fitur AAA server yang di miliki oleh mikrotik sesuai kepanjangan AAA (Authentication,, Authorization dan Accounting), user manager memiliki database yang bisa digunakan untuk melakukan autentikasi user yang login kedalam network yang ada, memberikan kebijakan terhadap user tersebut. Misalnya limitasi Transfer rate, dan juga pembatasan hak akses yang akan dilakukan nantinya

1. Melakukan konfigurasi Router Detail adar usermanager dapat digunakan oleh mikrotik. IP address yang digunakan harus sesuai dengan IP yang ada di RADIUS Server.

2. Melakukan konfigurasi Limitation Detail untuk limitasi bandwidth dan uptime user pada voucher.

3. Konfigurasi profil digunakan untuk membantu proses generate voucher agar voucher yang di buat sesuai dengan profile yang telah di tentukan.

4. Setelah selesai maka di lakukan proses generate voucher untuk membuat user yang akan di gunakan untuk login ke hotspot, dan menggunakan profile yang telah dibuat.

d) Pembatasan Hak Akses Internet dengan Web Proxy

Selanujutnya adalah dengan melakukan pembatasan hak akses dengan menggunakan fitur mikrotik yaitu web proxy, dengan membatasi user dalam mengakases situs-situs yang mengandung unsur pornografi, dan judi online. Pembatasan hak akses diilakukan terhadap kontenm setiap website yang mengandung konten yang masuk ke dalam table filter tidak bisa akses. Berikut adalah beberapa konten yang di blokir oleh router mikrotik.

\section{Kesimpulan}

Dari penelitian diatas yang berjudul Implementasi Jaringan Hotspot perkantoran guna meningkatkan keamanan jaringan komputer, dapat disimpulkan bahwa dengan Mikrotik RouterOS dapat dibangun fasilitas hotspot berbasis mikrotik pada jaringan Perkantoran. Penggunaan fitur Mikrotik RouterOS dapat memberikan 
manfaat dalam membatasi user/pelanggan yang dapat melakukan koneksi internet melalui jaringan hotspot. Dengan menggunakan metode Simple Queue yang terdapat pada fitur MikroTik RouterOS, bandwidth terbagi secara merata pada setiap pelanggan sehingga tidak terjadi tarik menarik bandwidth antar pelanggan. Pembuatan paket voucher dengan menggunakan fitur User Manager pada Mikrotik RouterOS dapat secara efektif membatasi penggunaan bandwidth pelanggan berdasarkan waktu akses yang tertera pada paket voucher. Dengan menggunakan fitur Torch dan Graphing yang terdapat pada menu Tools, Admin perkantoran dapat me-monitoring trafik bandwidth sebagai bagian dari kegiatan maintenance pada jaringan hotspot.

\section{Daftar Pustaka}

[1] Y. W. Aswin, M. Mudjianto, and R. Ningsih, "Sistem Informasi Inventory Pada Hotel Maharani," J. Nas. Komputasi dan Teknol. Inf., vol. 3, no. 3, pp. 289-295, 2020.

[2] A. A. Mamusung, N. B. Anshary, and R. A. Sumarni, "Perancangan Sistem Monitoring Gangguan Akses Wifi. Id PT Telkom Wilayah Jakarta Timur Berbasis Netbeans," J. Nas. Komputasi dan Teknol. Inf., vol. 3, no. 3, pp. 255-261, 2020.

[3] Y. Yanti, N. Pramita, and M. Maulizar, "Analisa Pengukuran Interferensi Pada Acces Point (Ap) Untuk Mengetahui Kualitas Quality of Service (Qos),” J. Nas. Komputasi dan Teknol. Inf., vol. 1, no. 1, 2018.

[4] M. Munawir, Z. Zulfan, S. Susmanto, and F. Furqan, "Analisis Quality Of Service (Qos) Layanan Video Streaming Youtube Pada Jaringan Wireless," J. Nas. Komputasi dan Teknol. Inf., vol. 3, no. 1, pp. 6467, 2020.

[5] S. Wijayanto, "Analisa perancangan model sistem monitoring, pencatatan dan pengiriman hasil produksi truk dengan Remote File Transfer System (RFTS) pada perusahaan XYZ menggunakan metode System Development Life Cycle,” J. Nas. Komputasi dan Teknol. Inf., vol. 3, no. 1, pp. 1-8, 2020. 